\section{ON HARDENED CHRYSALIS OIL}

\section{By Mrrsumaru Tsujtmoto}

Received August 2, 1915

Raw chrysalis oil is unsuitable for the purpose of hydrogenation, as its nitrogenous and other impurities largely affect the activity of the catalyzer, even if we neglect the dark color and bad odor of the oil. However, the refining of chrysalis oil is by no means an easy one; but the process proposed by the author, which essentially consists in heating the oil with 5 to ro per cent by vol. of dilute sulfuric acid (sp. gr. I.39) and then treating it with Kambara earth, gives an excellent result. ${ }^{1}$ The refined oil hardened by nickel catalyzer is a white fat which may be used as a useful raw material for soap-making.

The composition of chrysalis oil has been as yet little investigated. The results of experiments published by the author some years ago appear to be the only report on this subject. ${ }^{2}$ According to this report, the fatty acids of chrysalis oil consist of about 25 per cent saturated and 75 per cent unsaturated acids (iodine value 178.73 ). Among the saturated acids, palmitic acid was identified; stearic acid is probabiy not present. The unsaturated acids consist of oleic, linolenic and isolinolenic acids; besides them, some isomers of linolic acid are present in a somewhat large quantity.

If the conclusion of the above-mentioned investigation be really the case, the final product of the hydrogenation of these unsaturated acids must be stearic acid. A study of the product is. important from the point of view of utilizing the hardened chrysalis oil for technical purposes. The author made a few experiments which are described below.

I-HYDRogenation OF THE CNSATURATED (LIQTid) FATTY ACIDS OF CHRYSALIS OIL

Fifty grams of chrysalis oil ${ }^{3}$ were saponified in a flask with $38 \mathrm{cc}$. of 50 per cent aqueous solution of $\mathrm{KOH}$ and II $3 \mathrm{cc}$. of 96 per cent alcohol, by warming on a water bath; the excess of alkali was neutralized with acetic acid and $500 \mathrm{cc}$. of 7 per cent aqueous lead acetate solution was stirred into. The resulting lead soap was twice washed with $500 \mathrm{cc}$. of hot water and treated with $500 \mathrm{cc}$. of ether at $10^{\circ} \mathrm{C}$. and then filtered (Torte11i and Ruggeri's method). The filtrate was then treated with dilute $\mathrm{HCl}$, in order to decompose the lead soap, and was well washed with water: $250 \mathrm{cc}$. of the ethereal solution of the free unsaturated acids thus obtained, which contains about $20 \mathrm{~g}$. of the acids of iodine value $x 76.17$, were transferred into a strong glass bottle; $0.5 \mathrm{~g}$. of Loew's platinum black was added.

The bottle was then connected to a hydrogen holder. ${ }^{4}$ On expelling the air from the bottle by hydrogen; it was strongly shaken by means of a

1 J. Chem. Ind., Tokyo, 17, No. 191; Chem. Rev., 1914, 58.

2 J. Coll. Eng., Tokyo, 4 (1908), No. 3; J. Soc. Chem. Ind., 1908, 455.

3 This sample of the oil was procured from an oil factory in Ibaraki prefecture. It had the following properties: acid value 104.84 , saponification value 187.03 , and iodine value (Wijs) 140.33 .

1 Hydrogen was prepared by pure zinc and dilute $\mathrm{H}_{2} \mathrm{SO}_{4}$, and passed through the wash bottles containing concentrated potassium permanganate solution and concentrated $\mathrm{H}_{2} \mathrm{SO}_{4}$ mechanical contrivance. After $3 \frac{1}{2}$ hrs. shaking, a loss of about $2900 \mathrm{cc}$. of hydrogen was observed on the holder. Here the hydrogenation was stopped for a time. On evaporating of the ether, a residue amounting to $17.52 \mathrm{~g}$. was obtained. It was a brown-yellow crystalline mass which when melted formed a brownred liquid; it melted at $56.2^{\circ} \mathrm{C}$, having the neutralization value 188.92 and iodine value $45.9 \mathrm{I}$. The hy. drogenation was apparently incomplete; but before continuing the operation, it was found better to remove the unsaponifiable and coloring matters from the product.

Eleven grams of the above product were saponified with 50 cc. of 8 per cent alcoholic solution of $\mathrm{NaOH}$; then $5 \mathrm{~g}$. of $\mathrm{NaHCO}_{3}$ and about $5 \circ \mathrm{g}$. of pure sand were thoroughly mixed with it. The mass was dried, powdered and exhausted in a Soxhlet extractor with petroleum ether.

The crude unsaponifiable matter thus extracted was 2.22 per cent. The soap in the extractor was dissolved in hot water and decomposed with dilute $\mathrm{HCl}$ and then taken up with ether. The ethereal solution of the fatty acids which appeared brownish yellow, was decolorized with animal charcoal, and made up to $250 \mathrm{cc}$. by adding ether; then adding $0.3 \mathrm{~g}$. of the platinum black, it was hydrogenized for 2 hrs. in the same way as before (the reading of the volume of hydrogen was omitted).

On evaporating off the ether, $8.3 \mathrm{~g}$. of the hydrogenated acids were obtained. The white crystalline mass had a melting point of 68 to $68.5^{\circ} \mathrm{C}$., neutralization value 195.19 and iodine value 0 . This product is therefore a saturated compound, which in its $\mathrm{m}$. p. and neutralization value nearly coincides with stearic acid (m. p. $69.3^{\circ} \mathrm{C}$, neutralization value 197.5 , molecular wt. 284). A mixture of the product with about an equal quantity of pure stearic acid melted at 68 to $68.3^{\circ} \mathrm{C}$.

In order to perform the fractional crystallization. of the acids, $5 \mathrm{~g}$. of the hydrogenated product were dissolved in roo cc. of 90 per cent alcohol and separated into three portions successively as follows:

(1) $4.27 \mathrm{~g}$; white laminae with pearly luster; tn. p. 69.5 to $70^{\circ} \mathrm{C}$.; neutralization value 197.82 ; mean mol. wt. 283.59. A mixture with pure stearic acid melted at 69.5 to $69.7^{\circ} \mathrm{C}$.

(2) $0.21 \mathrm{~g} ; \mathrm{m} . \mathrm{p} .68^{\circ} \mathrm{C}$; neutralization value 197.20

(3) Residue left on evaporating the mother liquor, $0.41 \mathrm{~g}$; a little colored solid; m. p. $50^{\circ} \mathrm{C}$; neutralization value 177.42 .

The low $m$. p. and neutralization value are probably due to the accumulation of the impurities in this part and also to the esterification of the acids on evaporating off alcohol.

The result of the elementary analysis of (I) was as follows:

0.1245 gave $0.3487 \mathrm{CO}_{2}$ and $0.1439 \mathrm{H}_{2} \mathrm{O} ; \mathrm{C}=76.39 ; \mathrm{H}=12.84$

$\mathrm{C}_{18} \mathrm{H}_{36} \mathrm{O}_{2}$ requires $\mathrm{C}=76.06 ; \mathrm{H}=12.68$.

Therefore, the substance was confirmed to be stearic acid.

From the above experiment, it was concluded that the hydrogenated product of the unsaturated fatty acids of chrysalis oil consists mainly of stearic acid. 


\section{II-ON THE SATURATED (SOLID) FATTY ACIDS OF CHRYSALIS OII}

Although the saturated acids have no direct relation to hydrogenation, an experiment supplementary to the former investigation ${ }^{1}$ was performed as follows: The impure lead soap of the solid fatty acids obtained in the previous experiment on the liquid acids, was carefully detached from the filter paper and heated in a beaker with dilute $\mathrm{HCl}$. The acids were then dissolved in ether and decolorized with animal charcoal. The crude solid acid which was left on evaporating off the ether, formed a yellow colored crystalline mass. The yield amounted to I I. $5 \mathrm{~g}$.

By dissolving in $100 \mathrm{cc}$. of 96 per cent alcohol, it was fractionally crystallized into five parts.

(1) $3.78 \mathrm{~g}$; granular crystals; on melting, solidifies to a grayish white mass; m. p. $55-55.5^{\circ} \mathrm{C}$; nelutralization value 205.09 .

(2) $1.40 \mathrm{~g}$; m. p. $55.5-56^{\circ}$ C.; neutralization value 209.30 .

(3) $0.77 \mathrm{~g}$; somewhat granulat crystals, faintly yellow; m. p. $56.5^{\circ} \mathrm{C}$. neutralization value 210.70 .

(4) $0.21 \mathrm{~g}$; pale yellow laminae; m. p. $57^{\circ} \mathrm{C}$.

(5) $3.61 \mathrm{~g}$; residue from the mother liquor; an orange-yellow soft mass.

A mixture of $3 \mathrm{~g}$. consisting of $2.2 \mathrm{~g}$. of (I) and 0.8 g. of (2) was dissolved in Ioo cc. of 96 per cent alcohol and fractionally precipitated with magnesium acetate into the following fractions:

(1) 0.9895 g.; m. p. $55.5^{\circ} \mathrm{C}$; neutralization value 203.22 ; thean mol. wt. 276.05 .

(2) 0.4920 g.; m. p. $56^{\circ} \mathrm{C}$; neutralization value 205.43 ; mean mol. wt 273.09 .

(3) 0.4305 g.; m. p. $59^{\circ} \mathrm{C}$; neutralization value 207.98 ; mean mol wt. 269.74 .

(4) 0.4785 g.; m. p. $60.5-61^{\circ}$ C.; neutralization value 215.25 ; mean mol. wt. 260.16

(5) No precipitate was obtained by adding an excess of the precipitant. Therefore, it was abandoned. (The acid contained in this part corresponds to $0.6095 \mathrm{~g}$.)

The result is not decisive, but it is certain that an acid or acids higher than palmitic are present. The mean molecular weight of about 270 seems to point to the presence of daturic acid, $\mathrm{C}_{17} \mathrm{H}_{34} \mathrm{O}_{2}$, But as by repeated precipitations, the $\mathrm{m}$. $\mathrm{p}$. and neutralization values are regularly changed a little, it is more probable that the substance under examination consists of an eutectic mixture of stearic and palmitic acids.

III-DETECTION OF HIGHER SATURATED FATTY ACIDS IN HARDENED CHRYSALIS OIL

To decide whether the hardened chrysalis oil contains saturated acids higher than stearic, the author applied the method proposed by $H$. Kreis and $E$. Roth $^{2}$ which had been modified and applied to the analysis of the hardened oil by $W$. Normann and $E$. Hugel. ${ }^{3}$

Ten grams of the mixed fatty acid obtained from a hardened chrysalis oilt (an oil from Nagano prefecture hardened by means of nickel catalyzer) were dissolved in roo cc. of 96 per cent alcohol in a flask. By heating it on a water bath, $0.75 \mathrm{~g}$. of lead acetate dissolved in $50 \mathrm{cc}$. of alcohol was added. On cooling the solution to the room temperature $\left(20^{\circ} \mathrm{C}\right.$.), it was soon

I Loc. cit.

${ }^{2}$ Chem.-Ztg., 1913, 58

Ibid., 1918, 815

- Chem. Rev., 1914, 58. This sample is the No. B hardened oil. Its properties are as follows: $\mathrm{m} . \mathrm{p}, 56^{\circ} \mathrm{C}$; acid value 57.16 ; saponification value 190.71 ; iodine value 35.81 filtered through a filter paper; the precipitated lead salt was washed well with alcohol and decomposed by dilute hydrochloric acid. The free acid was taken up with ether, and washed free from the mineral acid; the ether was then evaporated and a white solid acid was left.

It was dissolved in $25 \mathrm{cc}$. of 90 per cent alcohol and cooled to room temperature for $30 \mathrm{~min}$. The mother liquor was filtered off; the deposited crystals were dried by pressing between dry filter papers. It was then twice dissolved in $I 2.5 \mathrm{cc}$. and $6 \mathrm{cc}$, respectively, of 90 per cent alcohol by repeating the same treatment as above.

The final deposit weighed $0.35 \mathrm{~g}$. and consisted of nacreous laminae; m. p. $69.5-70^{\circ} \mathrm{C}$.; neutralization value I 94.76 . This substance was, therefore, identified as stearic acid. No saturated acid higher than stearic was found in the hardened chrysalis oil. This result is in a good accordance with that obtained in the previous experiment.

IV-INNER IODINE VALUE OF HARDENED CHRYSALIS OIL

It has been shown by J. Marcusson and G. Meyerheim, ${ }^{1}$ that the inner iodine values of hardened fish oils are higher than Ioo, whereas lower values are found in the cases of hardened terrestrial animal oils. With a sample of "Talgol" which is of fish oil origin, they found a value of Io7.

While belonging to a class of terrestrial animal oils, as chrysalis oil has a high iodine value, it appears not unlikely that the inner value of the hardened product still exceeds Ioo, and so in this respect it may resemble fish oils. To determine this, the author used the following two oils for examination:

(A) The same sample used in the previous experiment III.

(B) A hardened oil having the following properties: m. p. $56-56.5^{\circ} \mathrm{C}$; acid value 57.46 ; saponification value I91.08; iodine value 45.53. [The original chrysalis oil was the same as (A), the time of hydrogenation only being different.]

Three grams of the sample were treated in a manner equivalent to Tortelli and Ruggeri's method. After keeping at 6 to $10^{\circ} \mathrm{C}$. for $2^{1 / 2} \mathrm{hrs}$, the ether solution of the lead soap was filtered off and decomposed with hydrochloric acid.

The iodine values were determined by Wijs' method. The inner iodine value of Sample $A^{2}$ was 87.60; of Sample B, I03.22, nearly approaching that of "Talgol.",

In spite of the low iodine value (45.53) of Sample B, the inner value was comparatively very high. So, for a sample of the hardened chrysalis oil which has an iodine value near to that of "Talgol" (iodine value 65 to 70 ), a still higher inner value may be expected.

Of course, the process of hydrogenation, $i . e$. , the catalyzer, temperature, time, and method of stirring, etc., will essentially influence the inner iodine value

1 Z. angev. Chem., 1914, 201.

2 The liquid fatty acids of this sample obtained as above, solidified at the room temperature. It seems, therefore, to have contained more or less solid fatty acids. 
of the product. That hycrogenation takes place by degree according to the unsaturation of the fatty acids, will not always be anticipated. It will be, therefore, unsafe to attach too much importance to the inner iodine value of a hardened oil without taking into account the iodine value of the oil itself. For hardened chrysalis oil of an iodine value above 50, an inner iodine value exceeding too may probably be expected.

$$
v-S U M M A R Y
$$

The results of the present investigations may be summarized as follows:

I-The hydrogenated product of the unsaturated fatty acids of chrysalis, oil consists mainly of stearic acid.

II-Besides palmitic acid, some higher saturated acid or acids are present in chrysalis oil. This substance is probably an eutectic mixture of stearic and paimitic acids.

III-By the Kreis and Roth method, no saturated acid higher than stearic was found in the hardened chrysalis oil.

IV-An inner iodine value exceeding roo may probably be expected in the case of a hardened chrysalis oil having the iodine value above 50 .

INDUSTRIAL EXPERIMENT STATION TOKYO, JAPAN

THE USE OF DIPHENYL GLYOXIME AS AN INDICATOR IN THE VOLUMETRIC DETERMINATION OF NICKEL BY FREVERT'S METHOD

By G. I. KELLEY AND J. B. CONANT

Received December 2, 1915

A volumetric method for determining nickel in iron and steel as devised by H. L. Frevert was published in Blair's "Chemical Analysis of Iron," 7th edition, I9I2. Since that time the method has been constantly in use in this laboratory, but inasmuch as some small changes have been made from time to time it seems best to republish the method with these modifications. Accordingly we give below Frevert's method as originally proposed, except for the modifications mentioned above, and follow it with a discussion of the use of diphenyl glyoxime as an indicator.

FREVERT'S METHOD FOR THE DETERMINATION OF NICKEL IN STEEL

(A) SOLUTION OF THE SAMPLE-For ordinary nickel steels, a $x-g$. sample is taken, but with less than 0.I0 or more than 5 per cent of nickel, larger or smaller sarnples may be taken. In the absence of more than small amounts of chromium, solution is most rapid in $50 \mathrm{cc}$. of hot dilute nitric acid (sp. gr. r.r3), but with chromium present in amounts greater than 0.5 per cent, or under circumstances where chromium carbides are present, more satisfactory results are obtained by dissolving the sample in $60 \mathrm{cc}$. of dilute hydrochloric acid ( $I: I$ ) with the aid of heat. When solution is complete, the iron and the carbides are oxidized by adding nitric acid, drop by drop, until effervescence ceases. Boiling removes the products resulting from the decomposition of the nitric acid after which the solution is cooled. The quantities of acid given here are those which are convenient for use with samples of I $g$. or less.

(B) PRECIPITATION OF NICKEL DIMETHYL GLYOXIMEThe solution obtained, as described above, is rapidly cooled by the addition of a lump of ice, after which are added in succession, $\mathrm{I} 2 \mathrm{~g}$. of citric acid or equivalent solution, 20 cc. ammonia water (sp. gr. 0.90), sufficient solution of dimethyl glyoxime to precipitate all nickel present and enough more ammonia to make the solution distinctly ammoniacal. The mixture is thoroughly stirred after each of these additions. The solution of dimethyl glyoxime is prepared by dissolving $20 \mathrm{~g}$, of the reagent in $1300 \mathrm{cc}$. of ammonia water (sp. gr. 0.90), after which enough water is added to bring the volume up to $2000 \mathrm{cc}$. Ten cc. of this solution allow sufficient excess to completely precipitate 1.5 per cent of nickel in a I-g. sample, $i . e$, about $0.0150 \mathrm{~g}$. of nickel.

(c) TREATMENT OF NICKEL DIMETHYL GLYOXIME PRECIPITATE-When the amount of nickel is small (0.10 per cent or less), time must be allowed for complete precipitation - an hour is usually ample. With amounts larger than this, no danger of low results attends immediate filtration. For this purpose an asbestos mat on a 2 -in. perforated porcelain plate or a Buchner funnel may be used. The solution containing the suspended precipitate will usually have a volume of 200 to $250 \mathrm{cc}$. It should be stirred thoroughly and poured on to the asbestos mat in such a way that the funnel always remains partly filled with liquid. Strong suction should be avoided. Quantities of precipitate corresponding to less than 5 per cent of nickel in a $\mathrm{x}-\mathrm{g}$. sample rarely cause trouble in filtering, but the difficulty rapidly increases with larger amounts. When all of the precipitate has been transferred to the asbestos, it is thoroughly washed. with water. Both wash water and filtrate are discarded, although the latter may be tested with dimethyl glyoxime if it is believed that all of the nickel may not have been precipitated.

(D) SOLUTIOA AND DECOMPOSITION OF THE PRECIPITATE-C.The receiving flask and tip of the funnel are next well rinsed with water. With the mat still in place, but with suction off, enough nitric acid is added to cover the asbestos to a depth of $1 / 8$ in. After a minute, suction is applied, the acid drawn through the filter and about as much more added, taking care to cover the entire surface. At this point there should remain no visible trace of the red precipitate. The mat is now to be thoroughly washed with water, the washings being collected in the flask with the acid. The solution so obtained is then transferred to a $400 \mathrm{cc}$. beaker in which it is heated to boiling. Here the solution is allowed to cool slightly to facilitate the addition of I $g$. of either potassium chlorate or ammonium persulfate. The solution is boiled until clear; this usually involves a considerable reduction in bulk, often as much as 50 per cent. Insufficient boiling may cause trouble (I) through failure to decompose the dimethyl glyoxime, which would reprecipitate when the solution is subsequently made ammoniacal, or (2) because if the solution is not freed from oxidizing products 